\title{
APPLICATION OF IMAGE ANALYSIS TO ASSESSING CRITICAL PORE SIZE FOR PERMEABILITY PREDICTION OF CEMENT PASTE
}

\author{
Jing Hu AND PIET STROEVEN \\ Faculty of Civil Engineering and Geosciences, Delft University of Technology, $2628 \mathrm{CN}$ Delft, the Netherlands \\ e-mail: j.hu@citg.tudelft.nl, P.Stroeven@ct.tudelft.nl \\ (Accepted March 19, 2003)
}

\begin{abstract}
This paper explores image analysis techniques that provide insight into the nature of pore structure as observed in backscattered electron images of polished sections. On the basis of mathematical morphology, the pore size distribution is characterised and the critical pore size is determined for cement paste at different hydration time. The influence of image resolution is investigated. The permeability of cement paste can be predicted according to General Effective Media (GEM) theory. Comparison between permeability estimation and experiment results reveals good agreement.
\end{abstract}

Keywords: general effective media theory, image analysis, permeability, pore size distribution.

\section{INTRODUCTION}

Porosity and pore microstructure are among the most important features of the microstructure of cement paste that affect engineering properties such as strength and permeability. The interpretation of experimental results such as mercury intrusion porosimetry (MIP) data are restricted by assumptions about pore shape that are known to be a poor approximation of the complex, tortuous network of capillary pores in cement paste. Direct observations of pore structure through electron microscopy provide a useful and reliable alternative. Lange et al. (1994) indeed showed that mean perimeter length of pore clusters (obtained by image analysis of specimen sections) and fracture toughness of cement pastes and mortars with water cement $(\mathrm{w} / \mathrm{c})$ ratio of 0.4 can be linearly related.

The use of backscattered electron (BSE) imaging to study the microstructure of cement paste is a comparatively new technique (Lange et al., 1994; Scrivener, 1989; Ye et al., 2002). The amount and distribution of the microstructural constituents can be quantified by image analysis. Lange et al. (1994) explored several image analysis techniques such as sizing, two-point correlation, and fractal analysis, and studied the relationship between pore microstructure and material properties. With particular interest in the mechanical behaviour of the cement-based material, the data sets of individual pores were truncated to include only major pore clusters with an area larger than 10 $\mu \mathrm{m}^{2}$. Such microstructural features significantly exceed the size traditionally associated with capillary porosity
$(0.05 \sim 10 \mu \mathrm{m})$. This method is not suitable when transport properties are of interest (e.g. permeability), which are generally considered to be strongly related to the presence of small capillary pores. In addition, many pores seen on a two dimensional section are interconnected above and below the plane of the section. It is therefore inappropriate to consider the profiles of pore areas as individual objects (Scrivener, 1989). Scrivener stated that far more suitable are the techniques of mathematical morphology developed by Serra et al. (1982). These techniques are based on measuring the changes produced when a binary image is transformed. The simplest mathematical morphological transformations are erosion, dilation, opening and closing. In this way, the pore size distribution in cement paste can be obtained.

According to Scrivener (1989), quantitative measurements relevant for macroscopic properties, such as permeability, can be made on 2D sections, even when the relationship between microstructure and macroscopic properties cannot be established theoretically or is only of empirical nature. In this study, the critical pore size is determined on the basis of the pore size distribution, and used to predict the permeability of cement paste with various $\mathrm{w} / \mathrm{c}$ ratios at different degrees of hydration. The estimation is compared to experimental results. The General Effective Media (GEM) theory was employed for this purpose. This theory was developed by McLachlan et al. (1990) to calculate the overall conductivity of bicomposite materials. The influence of image resolution is also briefly discussed. 


\section{IMAGE PROCESSING}

Cement paste specimens were prepared according to standard procedures. Three $\mathrm{w} / \mathrm{c}$ ratios were involved, $0.4,0.5$ and 0.6, respectively. For details, see Ye et al. (2002). 12 backscattered electron (BSE) images of random locations on the polished section of each paste specimen were employed as image files. Lange et al. (1994) proved that 12-image sets for cement paste provide a value for pore area fraction that is within a relative error of $15 \%$ of the true value within a $95 \%$ confidence level.

The physical size of the reference region of each image is $263 \mu \mathrm{m}$ in length and $186 \mu \mathrm{m}$ in width $(1424 \times 968$ pixels $)$. The original BSE image was segmented by applying a grey-level threshold to create a binary image reflecting the porous regions. The threshold grey level between porosity and solid phases was selected by a technique based on the shape of the histogram of BSE image. The unhydrous material and calcium hydroxide have fairly uniform grey levels, resulting in sharp peaks in the histograms. Due to variation in composition, the grey levels of the other hydration products (basically C-SH) form a more shallow, but still clearly identifiable peak in the histograms. It has been found that consistent results can be obtained by selecting an arbitrary point on the lower slope of the peak produced by the other hydration products (Scrivener, 1989). The binary image was then subjected to an image processing program for quantitative evaluation. A BSE image and the corresponding binary image for the cement paste with $\mathrm{w} / \mathrm{c}$ ratio of 0.5 at 3 days of hydration are given in Fig. 1.

\section{DETERMINATION OF CRITICAL PORE SIZE}

On the basis of mathematical morphology transformations, various distributions of pore phase can be obtained by using a sequence of similarly shaped structuring elements of increasing size. In this study, "opening distribution" is used whereby the binary image is opened by a series of squares of increasing size. The "opening distribution" curve of pore space is obtained by plotting the pore area fraction after an opening operation against the sidelength of structuring element. This gives a type of "size" classification in the case of an interconnected structure, in contrast to single features. This measure is a two dimensional analogue of the type of size distribution obtained by gas or methanol absorption or by low temperature calorimetry.

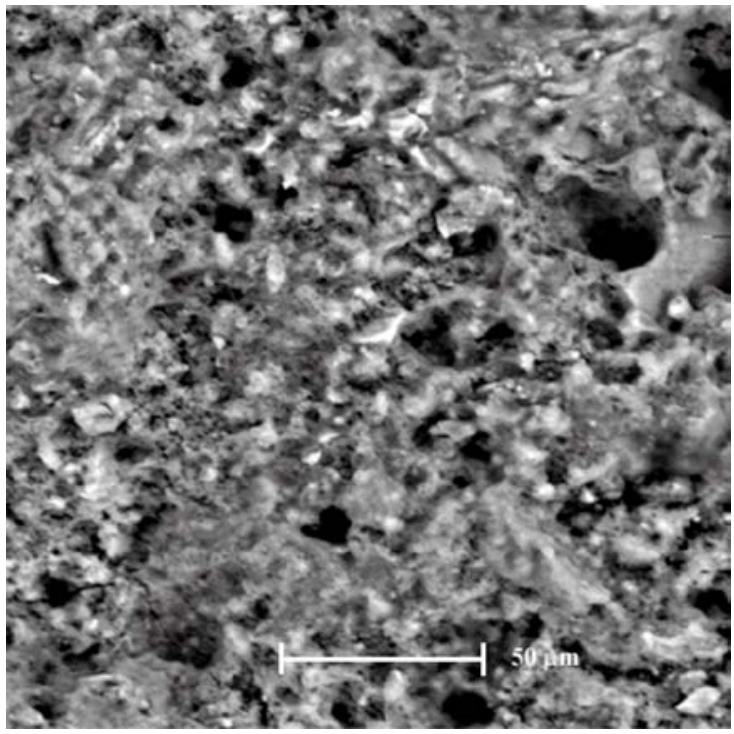

a) Original image

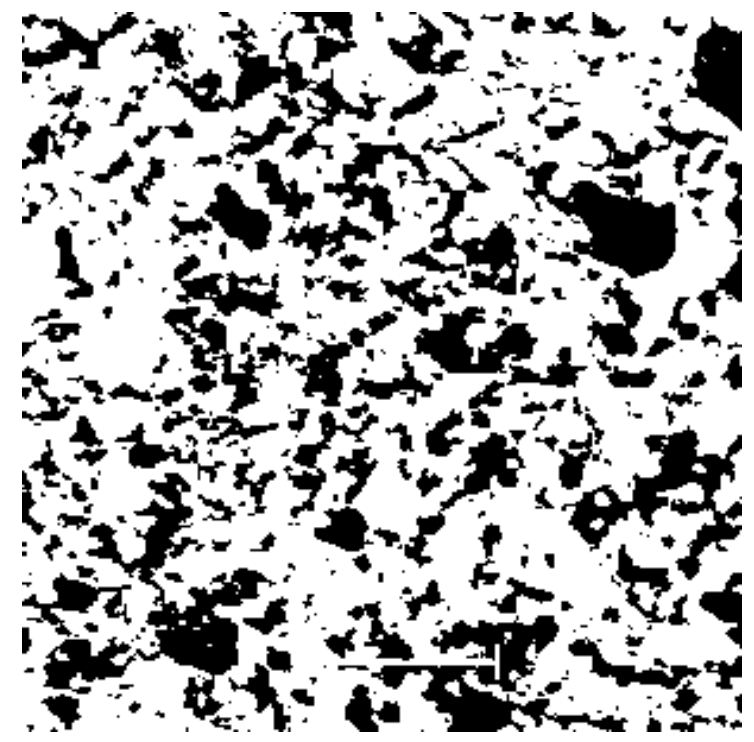

b) Binary image, porosity expressed by black

Fig. 1. BSE image of cement paste with water cement ratio of 0.5 at 3 days of hydration.

The definition of critical pore size can be found in the literature (Katz and Thompson, 1986; Cui and Cahyadi, 2001). The critical pore size $l_{\mathrm{c}}$ can be conceived as the diameter of the pore that completes the first interconnected pore pathway in a network developed by a procedure of sequentially adding pores of diminishing size to this network. It is generally accepted that the smaller the critical pore size, the finer the pore structure. The critical pore size is an unique transport length scale of major significance for permeability properties. Katz and Thompson (1986) supported the conjecture that mercury injection has a percolation geometry and 
considered the characteristic length $l \mathrm{c}$ as corresponding to the percolation threshold. It can be experimentally assessed by mercury intrusion porosimetry as in the work of Cui and Cahyadi (2001). A typical mercury injection curve, reflecting the volume percentage of mercury intruded as a function of the applied pressure, is S-shaped; after a gradual increase under rising pressure, a rapid rise in volume percentage of mercury intrusion occurs at a certain pressure, whereupon gradually a plateau value is reached. This stage of rapid rise is interpreted as the moment when the intruded mercury has formed the first connected cluster spanning the sample. The inflection point of the rapidly rising portion of the curve can be seen as the percolation threshold, expressed by the threshold pressure $P_{\mathrm{t}}$. Next, the characteristic length $l_{\mathrm{c}}$ is derived from the Washburn equation: $l_{\mathrm{c}}=-4 \gamma \cos \theta / P_{\mathrm{t}}$, where $\gamma$ is the surface tension $(=485 \mathrm{dyn} / \mathrm{cm}), \theta$ is the contact angle $\left(130^{\circ}\right)$. So, the critical pore size $l_{\mathrm{c}}$ can be associated with the inflection point of cumulative pore size distribution curve. In this study, the cumulative pore size distribution is obtained from the "opening distribution" analysis of specimen section. This inflection point is reflected by the peak of the derivative curve of "opening distribution" curve (pore area fraction after opening operation vs. size of structuring element).

\section{INFLUENCE OF RESOLUTION}

Small capillary pores play a very important role in the transport properties of cement specimens. Therefore, it is necessary to strike a balance between a representative area element revealing sufficiently large pore section, and a satisfactory resolution for detection of small capillary pores. The literature suggests applying a resolution of about $0.5 \mu \mathrm{m} /$ pixel for routine measurements of porosity from BSE images (Lange et al., 1994; Scrivener, 1989).

Fig. 2 and Table 1 reveal the influence of resolution on the accuracy of the critical pore size determined by the "opening distribution". The curves are derivatives of the cumulative pore size distribution curves (area percentage), whereby peaks arise at inflection points of the pore size distribution curves. The BSE images of cement paste (with w/c ratio of 0.35 ) at different resolutions are downloaded from the Internet (Stutzman, 1999).

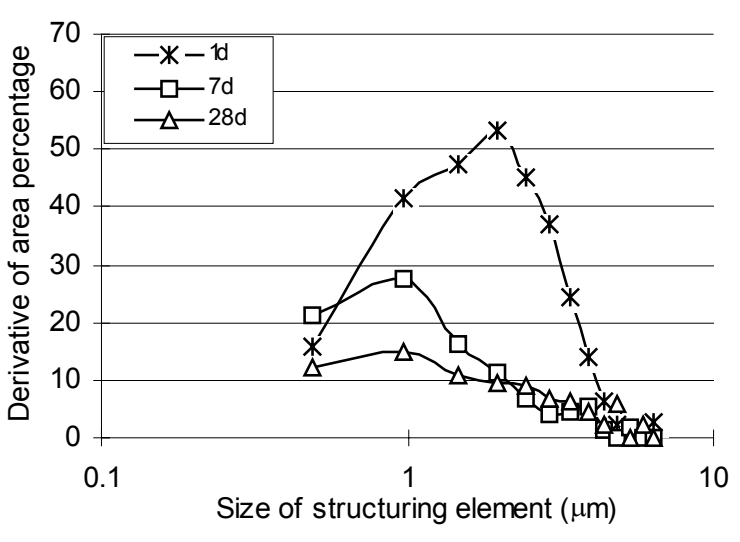

a) Resolution: $0.488 \mu \mathrm{m}$ per pixel

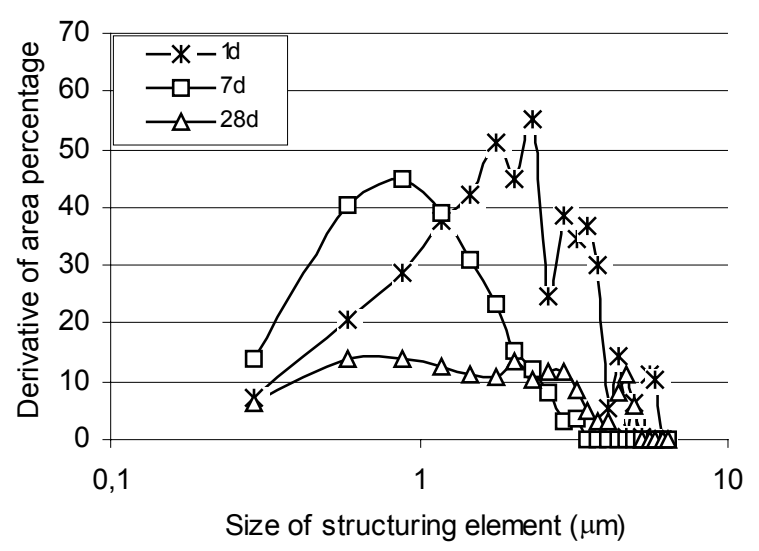

b) Resolution: $0.293 \mu \mathrm{m}$ per pixel

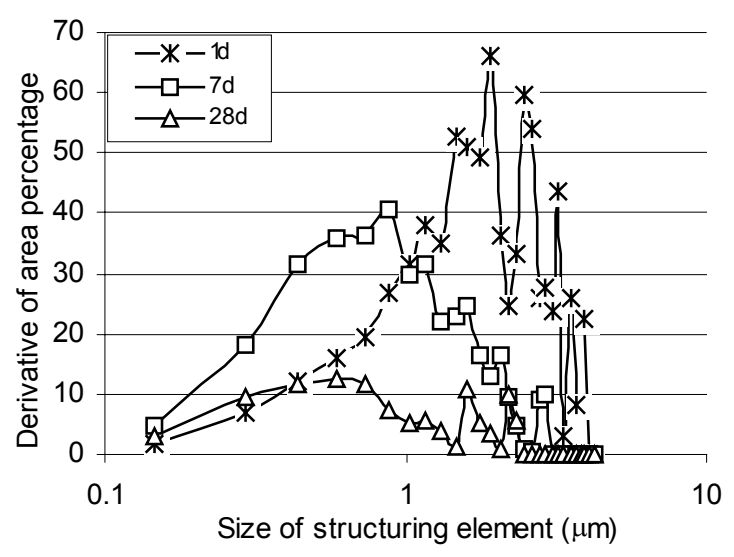

c) Resolution: $0.146 \mu \mathrm{m}$ per pixel

Fig. 2. Influence of resolution on the accuracy of determination of critical pore size by means of "opening distribution" curve, for cement paste with water cement ratio of 0.35 at 1, 7, 28 days of hydration. 
Table 1. Value of critical pore size at different hydration times (in $\mu \mathrm{m}$ ).

\begin{tabular}{lccc}
\hline $\begin{array}{l}\text { Resolution } \\
(\mu \mathrm{m} / \text { pixel })\end{array}$ & 1 day & 7 days & 28 days \\
\hline $0.488(600 \times)$ & 1.953 & 0.976 & 0.976 \\
$0.293(1000 \times)$ & 2.344 & 0.879 & 0.586 \\
$0.146(2000 \times)$ & 1.904 & 0.879 & 0.586 \\
\hline
\end{tabular}

A resolution of $0.488 \mu \mathrm{m} /$ pixel fails to differentiate the pore structure between 7 and 28 days of hydration. Although at the highest magnification $(2000 \times)$ trivial as well as subtle changes of the pore structure were revealed, resolutions of 0.293 and $0.146 \mu \mathrm{m} /$ pixel result in similar values of the critical pore size.

There exists some doubt as to the potentials of image analysis to study cement permeability that is generally associated with small capillary pores. Bágel (1997) investigated the relationship between pore structure (determined by mercury intrusion porosimetry) and permeability of pastes and mortars. He concluded that the fraction of pores between $100 \sim 10000 \mathrm{~nm}$ (i.e., $0.1 \sim 10 \mu \mathrm{m}$ ) is highly correlated with cement permeability (correlation coefficient of 0.953 ). For smaller pores in the $3.7 \sim 7500 \mathrm{~nm}$ range, the correlation coefficient declines to 0.883 . Therefore, it is reasonable to study cement permeability with image analysis techniques, as long as a satisfactory resolution of about $0.15 \sim 0.20 \mu \mathrm{m}$ per pixel is ensured. The resolution in this study is $0.185 \mu \mathrm{m} / \mathrm{pixel}$.

\section{PERMEABILITY PREDICTION}

The water permeability of cementitious materials is crucial to its durability. It is possible to measure the water permeability directly, but it is a timeconsuming operation, especially for mature pastes and concretes. As an alternative, some models (Cui and Cahyadi, 2001; Katz and Thompson, 1986) have been developed to relate water permeability to pore structure of cementitious materials. One commonly accepted approach to permeability estimation is by way of the Katz-Thompson equation (Katz and Thompson, 1986). However, it is found that application is far more difficult for cement pastes than for sandstones (El-Dieb and Hooton, 1994). This is due to the extremely complex nature of pore structures in the cement paste, as can be convincingly demonstrated by visual means (Stroeven, 1999; Ye et al., 2002). In the present study, the General Effective Media (GEM) theory is used to predict permeability of cement paste.
GEM theory considers cement paste as a two-phase composite material consisting of high-permeability capillary pores and a low-permeability phase including $\mathrm{C}-\mathrm{S}-\mathrm{H}$ gel, $\mathrm{CH}$, and unhydrous cement. Analogue to the overall conductivity of such a model material, the permeability will be governed by the volume fraction and the permeability of each phase. The detailed description of this theory and its application to cementitious materials can be found in references (McLachlan et al., 1990; Cui and Cahyadi, 2001).

At a given $\mathrm{w} / \mathrm{c}$ ratio and at a certain hydration stage, the overall permeability of cement paste can be estimated from data on porosity and critical pore size. Cui and Cahyadi (2001) calculated the paste permeability according to experimental results of mercury intrusion porosimetry. Comparison with direct permeability experiments revealed consistent results, which confirm that GEM theory is a useful tool in predicting the permeability of cementitious materials. The permeability of cement paste can be derived from the following equations:

$$
\begin{gathered}
\frac{(1-\phi)\left(k_{l}^{1 / 2}-k^{1 / 2}\right)}{k_{l}^{1 / 2}+A k^{1 / 2}}+\frac{\phi\left(k_{h}^{1 / 2}-k^{1 / 2}\right)}{k_{h}^{1 / 2}+A k^{1 / 2}}=0 \\
k_{h}=\frac{1}{226} l_{c}^{2}(1.8)\left(1-\phi_{c}\right)^{2} \\
k_{l}=k_{C-S-H}\left(1-\frac{1-\phi_{C-S-H}}{1-\phi_{c}^{\prime}}\right)^{2}
\end{gathered}
$$

where $k$ is the overall permeability of the cement paste, $k_{1}$ is the permeability of the low-permeability phase, $k_{\mathrm{h}}$ the permeability of the high-permeability phase (namely, capillary pores), $\phi$ is the porosity of the cement paste, $\phi_{\mathrm{c}}=0.18$ is the critical value of capillary porosity for percolation (Garboczi and Bentz, 1991), $l_{\mathrm{c}}$ is the critical pore size of the cement paste, $\mathrm{A}=\left(1-\phi_{\mathrm{c}}\right) / \phi_{\mathrm{c}}$ is a constant, $k_{\mathrm{C}-\mathrm{S}-\mathrm{H}}=7 \times 10^{-23} \mathrm{~m}^{2}$ is the permeability of the C-S-H gel (Powers, 1958), $\phi_{\mathrm{C}-\mathrm{S}-\mathrm{H}}$ is the volume fraction of the C-S-H gel in the solid phase of the cement paste, which can be calculated from $\mathrm{w} / \mathrm{c}$ ratio and porosity with Powers' model, and $\phi_{c}^{\prime}$ is the critical volume fraction of the $\mathrm{C}$ $\mathrm{S}-\mathrm{H}$, taken as $0.17 . k$ (in $\mathrm{m}^{2}$ ) is the intrinsic permeability of the cement paste. This material property is independent of the fluid used to measure it. Contrary, the permeability of the material is conventionally expressed in $\mathrm{m} / \mathrm{s}$ in experiments, whereby it depends both on the material properties and on the fluid characteristics. To compare the predicted permeability with experimental results, the intrinsic permeability 
$\left(k\right.$ in $\mathrm{m}^{2}$ ) can be converted into the conventional permeability $\left(k^{\prime}\right.$ in $\left.\mathrm{m} / \mathrm{s}\right)$ by the equation (Christensen et al., 1996): $k^{\prime}=k \rho g / \eta$, where $\rho\left(\right.$ in $\left.\mathrm{g} / \mathrm{cm}^{3}\right)$ and $\eta$ (in P) are the density and viscosity of the fluid, respectively, and $g$ (in $\mathrm{m} / \mathrm{s}^{2}$ ) is the acceleration of gravity. This equation can be specified by $k^{\prime}=9.79 \times 10^{6} k$ for water of $20^{\circ} \mathrm{C}$.

\section{RESULTS}

Overall measurement of the porosity is fairly straightforward as the area fraction measured on a $2 \mathrm{D}$ section is a direct estimate of the volume fraction (Underwood, 1968). Since the curves of "opening distribution" change with hydration time in a similar manner for different $\mathrm{w} / \mathrm{c}$ ratios, only the curves for $\mathrm{w} / \mathrm{c}=0.6$ paste are presented in Fig. 3. The critical pore size $l_{\mathrm{c}}$ is determined as shown in Fig. 4. The results for pastes of various w/c ratios at different hydration times are presented in Table 2.

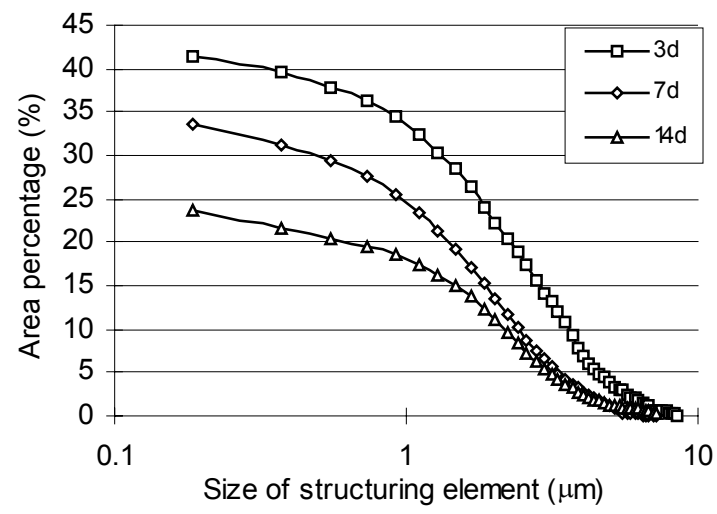

Fig. 3. Pore size distribution ("Opening distribution") curves for cement paste with water cement ratio of 0.6 at 3, 7, 14 days of hydration, respectively.

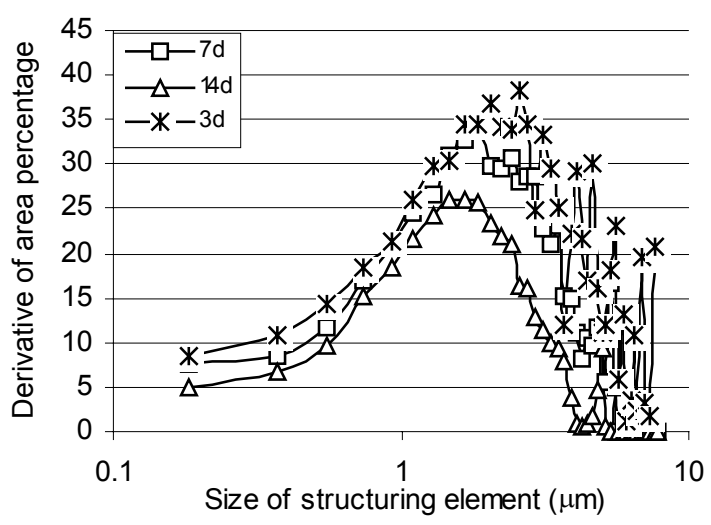

Fig. 4. Determination of critical pore size from derivatives of pore size distribution curves for cement paste with water cement ratio of 0.5 at 3, 7, 14 days of hydration, respectively. The maximum peak point corresponds to the inflection point on the pore size distribution curve.

\section{DISCUSSION}

Cui and Cahyadi (2001) reported a critical diameter of 0.069 and $0.010 \bullet \mathrm{m}$ for $\mathrm{w} / \mathrm{c}=0.3$ paste at the age of 7 and 210 days, respectively. The values for $\mathrm{w} / \mathrm{c}=0.4$ paste are $0.045 \bullet \mathrm{m}$ at 7 days, 0.036 - $\mathrm{m}$ at 35 days, and $0.010 \bullet \mathrm{m}$ at the age of 210 days. Cui and Cahyadi's data are based on mercury intrusion porosimetry, so they can be expected to yield lower values for the critical pore size than in the case of results obtained by image analysis. Although the two techniques revealed different orders of magnification for $l_{c}$, the same trend is found. The critical pore size decreases with hydration time. The higher the $\mathrm{w} / \mathrm{c}$ ratio, the larger the critical pore size. Hence, this approach allows studying the evolution of pore structure in cement paste with different $\mathrm{w} / \mathrm{c}$ ratios.

Table 2. Permeability of paste.

\begin{tabular}{c|c|c|c|c|c}
\hline \multirow{2}{w}{$/ \mathrm{c}$} & Age (days) & \multirow{2}{*}{$\begin{array}{c}\text { Porosity } \\
\phi(\%)\end{array}$} & $\begin{array}{c}\text { Critical size } \\
l_{\mathrm{c}}(\mu \mathrm{m})\end{array}$ & \multicolumn{2}{|c}{ Permeability } \\
\cline { 3 - 6 } & & 34.50 & 1.847 & $7.40 \times 10^{-16}$ & $\mathrm{in}(\mathrm{m} / \mathrm{s})^{*}$ \\
\hline \multirow{3}{*}{0.4} & 3 & 24.85 & 1.293 & $6.27 \times 10^{-9}$ \\
\cline { 2 - 6 } & 7 & 15.53 & 1.108 & $1.20 \times 10^{-21}$ & $6.14 \times 10^{-10}$ \\
\cline { 2 - 6 } & 14 & 33.18 & 2.586 & $1.23 \times 10^{-15}$ & $1.20 \times 10^{-14}$ \\
\hline \multirow{3}{*}{0.5} & 3 & 25.41 & 1.847 & $1.49 \times 10^{-16}$ & $1.46 \times 10^{-9}$ \\
\cline { 2 - 6 } & 7 & 18.46 & 1.478 & $6.12 \times 10^{-19}$ & $6.00 \times 10^{-12}$ \\
\cline { 2 - 6 } & 14 & 41.40 & 3.694 & $5.95 \times 10^{-15}$ & $5.83 \times 10^{-8}$ \\
\hline \multirow{3}{*}{0.6} & 3 & 33.46 & 2.401 & $1.10 \times 10^{-15}$ & $1.08 \times 10^{-8}$ \\
\cline { 2 - 6 } & 7 & 23.68 & 2.032 & $1.07 \times 10^{-16}$ & $1.04 \times 10^{-9}$ \\
\hline
\end{tabular}

*The intrinsic permeability (in $\mathrm{m}^{2}$ ) is also converted into $\mathrm{m} / \mathrm{s}$ for comparison purposes with experiments. 
The critical pore size reduces rapidly in the first 7 days (or so) of hydration, and then gradually decreases to a stable value. It is not possible to convert the opening distribution to a $3 \mathrm{D}$ size distribution, but it is useful, nevertheless, to measure the degree of difference between pore structures in cement pastes.

A study of Banthia and Mindess (1989) reveals permeability data of $1 \times 10^{-10}$ and $8 \times 10^{-13} \mathrm{~m} / \mathrm{s}$ for $\mathrm{w} / \mathrm{c}=0.35$ pastes after 7 and 28 days of hydration, respectively. Halamickova et al. (1995) reported the permeability of $\mathrm{w} / \mathrm{c}=0.4$ paste to be around $3.47 \times 10^{-}$ ${ }^{22} \mathrm{~m}^{2}$ at 28 days. For $\mathrm{w} / \mathrm{c}=0.5$ paste, Bier et al. (1989) found the water permeability to be $2 \times 10^{-10}$, $1 \times 10^{-10}$ and $3 \times 10^{-12} \mathrm{~m} / \mathrm{s}$, at 3,7 and 14 days, respectively. Ye (unpublished observations) found a permeability of $3.28 \times 10^{-8} \mathrm{~m} / \mathrm{s}$ for a paste with $\mathrm{w} / \mathrm{c}=0.6$ at 3 days of hydration. The results of permeability experiments depend to some extent on the testing conditions, so an excellent agreement between prediction and experiment is not possible. However, a relatively good consistency is found between permeability estimated by GEM theory and the experimental results.

It is interesting to compare the permeability estimation of GEM with that from Katz-Thompson equation. Christensen et al. (1996) calculated the permeability of $\mathrm{w} / \mathrm{c}=0.4$ cement paste by KatzThompson equation, yielding approximately $5 \times 10^{-10}$, $2 \times 10^{-11}$, and $1 \times 10^{-11} \mathrm{~m} / \mathrm{s}$, at 3,7 and 14 days, respectively. It is noteworthy that at 14 days hydration, the GEM theory gives a more reasonable estimation of $1.18 \times 10^{-14} \mathrm{~m} / \mathrm{s}$. This confirms that the GEM theory is more suitable for application to low-permeability materials like cement paste at later stage of hydration.

\section{CONCLUSION}

The size distribution and the critical pore size of the pore structure in cement based materials can be characterised by methods derived from quantitative image analysis and mathematical morphology. By means of GEM theory, the permeability of cement paste can be estimated from the porosity and critical pore size. Comparison with experimental data reveals that the GEM theory is especially useful for lowpermeability materials like more matured cement pastes.

\section{REFERENCES}

Bágel L, Živica V (1997). Relationship between pore structure and permeability of mortars. Cement and Concrete Research 27:1225-35.
Banthia N, Mindess S (1989). Permeability measurement on cement paste. In: Roberts LR and Skalny JP, eds. Proc. of Material Research Society Symposium 137; Boston, 173-9.

Bier TA, Ludirdja D, Young JF, Berger RL (1989). The effect of pore structure and cracking on the permeability of concrete. In: Roberts LR and Skalny JP, eds. Proc. of Material Research Society Symposium 137; Boston, 235-43.

Christensen BJ, Mason TO, Jennings HM (1996). Comparison of measured and calculated permeability for cement pastes. Cement and Concrete Research 26(9):1325-34.

Cui L, Cahyadi JH (2001). Permeability and pore structure of OPC paste. Cement and Concrete Research 31:277-82.

El-Dieb AS, Hooton RD (1994). Evaluation of the KatzThompson model for estimating the water permeability of cement-based materials from mercury intrusion porosimetry data. Cement and Concrete Research 24(3):443-55.

Garboczi EJ, Bentz DP (1991). Percolation of phased in a three-dimensional cement paste microstructural model. Cement and Concrete Research 21:325-44.

Halamickova P, Detwiler RJ, Bentz DP, Garboczi EJ (1995). Water permeability and chloride ion diffusion in portland cement mortars: Relationship to sand content and critical pore diameter. Cement and Concrete Research 25:790-802.

Katz AJ, Thompson AH (1986). Quantitative prediction of permeability in porous rock. Pyhs Rev B 34 (11):817981.

Lange DA, Jennings HM, Shah SP (1994). Image analysis techniques for characterization of pore structure of cement-based materials, Cement and Concrete Research 24 (5):841-53.

McLachlan DS, Blaszkiewicz M, Newnham RE (1990). Electrical resistance of composites. J Am Ceram Soc 73(8):2187-203.

Powers TC (1958). Structure and physical properties of hardened Portland cement paste. J Am Ceram Soc 41(1):1-6.

Scrivener KL (1989). The use of backscattered electron microscopy and image analysis to study the porosity of cement paste. In: Roberts LR and Skalny JP, eds. Proc. of Material Research Society Symposium 137; Boston, 129-40.

Serra J (1982). Image analysis and mathematical morphology. London: Academic Press.

Stroeven M (1999). Discrete Numerical Modelling of Composite Materials. PhD thesis, Delft University of Technology.

Stutzman PE (1999). The Concrete Microscopy Library, imaging in NIST. http://cee.ce.uiuc.edu/lange/micro/. 
Underwood EE (1968). Quantitative stereology. New Jersey: Addison-Wesley Publishing Company.

Ye G, Hu J, van Breugel K, Stroeven P (2002). Characterization of the development of microstructure and porosity of cement-based materials by numerical simulation and ESEM image analysis. Materials and Structures 35:603-613. 